\title{
EFFECT DOMINO KEBIJAKAN MONETER THE FRS AS TERHADAP PEREKONOMIAN INDONESIA
}

\author{
Tia Ichwani ${ }^{1}$, Rika Kaniati ${ }^{2}$, Hikmatul Husna ${ }^{3}$ \\ 1,2,3 Fakultas Ekonomi dan Bisnis, Universitas Pancasila \\ tiaichwani@univpancasila.ac.id \\ uqie2002@yahoo.com
}

Diterima 27 Juli 2018, Disetujui 12 September 2018

\begin{abstract}
Abstrak
Penelitian ini bertujuan untuk mengetahui pelaksanaan kebijakan moneter yang dilakukan oleh The Federal Reserve AS terhadap pergerakan suku bunga Bank Indonesia (BI 7 Days Repo), nilai tukar Rupiah terhadap Dollar AS, tingkat inflasi Indonesia dan nilai ekspor Indonesia. Metode penelitian yang digunakan adalah metode deskriptif kuantitatif dengan tujuan untuk membuat gambaran yang sistematis, faktual dan akrual mengenai fakta-fakta realiti pada tahun tersebut. Data yang digunakan adalah data sekunder, yaitu data-data yang bersifat historikal pada suku bunga the fed (FFR), inflasi, kebijakan moneter dan nilai tukar Rupiah.Dari hasil analisa dan pembahasan, dapat disimpulkan bahwa kebijakan moneter yang dilakukan oleh Pemerintah Amerika Serikat dalam menghadapi masalah perekonomiannya pada tahun 2017 - 2018 adalah dengan menaikan suku bunga the fed (FFR) secara berkala dan secara tidak langsung, hal ini mempengaruhi nilai Ekspor Indonesia.
\end{abstract}

Kata Kunci : SBI 7 Days Repo, Suku Bunga The Fed (FFR), Kebijakan Moneter.

\section{Abstract}

This study aims to determine the implementation of monetary policy conducted by The US Federal Reserve on the movement of interest rates of Bank Indonesia (BI 7 Days Repo), Rupiah exchange rate against US Dollar, Indonesia inflation rate and export value of Indonesia.The research method used is quantitative descriptive method with the aim to create a systematic, factual and accrual picture of the facts of reality in that year. The data used are secondary data, which are historical data on FFR, inflation, monetary policy and rupiah exchange rate.From the results of the analysis and discussion, it can be concluded that the monetary policy undertaken by the United States Government in dealing with its economic problems in 2017 - 2018 is to raise the federal rate (FFR) periodically and indirectly, this affects the value of Indonesian exports.

Keywords: SBI 7 Days Repo, Federal Rate (FFR), Monetary Policy. 


\section{PENDAHULUAN}

\section{Latar Belakang Masalah}

Sejumlah peristiwa besar dibidang ekonomi didunia membuat ekonomi global dalam ketidakpastian, seperti langkah Inggris yang memutuskan keluar dari keanggotaan Uni Eropa, Bank of Japan yang menerapkan suku bunga negatif hingga keputusan kenaikan suku bunga oleh Federal reserve Amerika Serikat. Berbagai peristiwa tersebut memberikan tekanan terhadap ekonomi di masingmasing Negara didunia, termasuk dinegara emerging market yang salah satunya adalah Indonesia.

Amerika Serikat mempunyai pengaruh besar pada kestabilan ekonomi dunia melalui bank Sentral The Federalnya. Kekuatan yang dimiliki bank Sentral The Fed sangat besar terutama pada pasar modal dunia. Saat ini The Federal Reserve AS merupakan nahkoda bagi kebijakan moneter di Amerika Serikat, sehingga perekonomian dunia saat ini bergantung pada kondisi bank dunia dan perekonomian di Amerika Serikat. Dengan demikian dapatlah dikatakan bahwa kebijakan yang dilakukan oleh The Federal Reserve AS kerapkali menimbulkan dampak positif maupun negative bagi sebagian Negara di seluruh dunia termasuk Indonesia.

\section{KAJIAN TEORI}

\section{Kebijakan Stabilisasi Ekonomi}

Pertumbuhan ekonomi mengukur prestasi dari perkembangan suatu perekonomian. Pengukuran akan kemajuan sebuah perekonomian memerlukan alat ukur yang tepat, berupa alat pengukur pertumbuhan ekonomi antara lain yaitu Produk Domestik Bruto (PDB) atau di tingkat regional disebut dengan Produk Domestik Regional Bruto (PDRB) yaitu jumlah barang atau jasa yang dihasilkan oleh suatu perekonomian dalam jangka waktu satu tahun dan dinyatakan dalam harga pasar.

Menurut ekonom klasik, Smith (1723-1970) pertumbuhan ekonomi secara klasik dipengaruhi oleh dua faktor utama yakni pertumbuhan output total dan pertumbuhan penduduk. Pertumbuhan ekonomi sangat dipengaruhi oleh produktivitas sektor-sektor dalam menggunakan faktor-faktor produksinya. Produktivitas dapat ditingkatkan melalui berbagai sarana pendidikan, pelatihan dan manajemen yang lebih baik (Sukirno, 2008).

Menurut teori pertumbuhan neo klasik tradisional, pertumbuhan output selalu bersumber dari satu atau lebih dari tiga faktor yakni kenaikan kualitas dan kuantitas tenaga kerja, penambahan modal (tabungan dan investasi) dan penyempurnaan teknologi (Todaro dan Smith, 2008).

Pertumbuhan ekonomi merupakan hasil dari dalam sistem ekonomi. Kemajuan teknologi merupakan hal yang endogen, pertumbuhan merupakan bagian dari keputusan pelaku-pelaku ekonomi untuk berinvestasi dalam pengetahuan. Peran modal lebih besar dari hanya sekedar bagian dari pendapatan apabila modal yang tumbuh bukan hanya modal fisik saja tapi menyangkut modal manusia. Akumulasi modal merupakan sumber utama pertumbuhan ekonomi (Mankiw, 2006). Daftar acuan 10 tahun terakhir.

Laju pertumbuhan penduduk dan hal-hal yang berhubungan dengan kenaikan jumlah angkatan kerja (labor force) secara tradisional telah dianggap sebagai faktor yang positif dalam merangsang pertumbuhan ekonomi. Teori neoklasik menyatakan bahwa tenaga kerja merupakan salah satu faktor yang menjelaskan tinggi rendahnya pertumbuhan ekonomi. Sodik et al (2007) dalam penelitiannya berusaha memeriksa pengaruh aglomerasi dalam pertumbuhan ekonomi regional. Hasilnya menunjukkan bahwa pertumbuhan ekonomi regional salah satunya dipengaruhi oleh angkatan kerja.

Selain jumlah penduduk, peran tenaga kerja terhadap pertumbuhan PDB juga sangat tergantung pada kualitas tenaga kerja tersebut. Teori Human Capital menjelaskan bahwa seseorang dapat meningkatkan penghasilannya melalui jenjang pendidikan yang lebih tinggi.

Ekonomi yang berorientasi ekspor dapat dipahami melalui export-led growth yang merupakan kebijakan ekonomi dan perdagangan yang bertujuan untuk mempercepat proses industrialisasi suatu negara dengan mengekspor barang-barang yang memiliki keunggulan komparatif (Buletin Ekonomi Moneter dan Perbankan, Juli 2013).

Export-led growth merupakan strategi ekonomi yang digunakan oleh beberapa Negara berkembang. Strategi ini berusaha untuk menemukan ceruk dalam perekonomian dunia untuk ekspor jenis tertentu.

Faktor lain yang berpengaruh terhadap pertumbuhan ekonomi adalah tingkat harga. Dalam perekonomian, proses meningkatnya harga-harga secara umum dan terus-menerus terkait dengan proses dan mekanisme yang terjadi dalam pasar, yang berpengaruh terhadap penurunan nilai mata uang.

\section{Kebijakan Moneter dan Kegiatan Ekonomi}

Kebijakan Moneter Kualititatif, Kebijakan Moneter Kualitatif adalah langkah-langkah bank sentral yang tujuan utamanya adalah untuk 
mempengaruhi jumlah penawaran uang dan suku bunga dalam perekonomian. Dalam masa Deflasi penawaran uang perlu ditambah. Langkah ini akan menurunkan suku bunga dan penurunan ini selanjutnya akan menggalakkan perkembangan kegiatan ekonomi sehingga tingkat kesempatan kerja menjadi lebih tinggi dan pengangguran berkurang. Dalam masa inflasi, pengeluaran masyarakat adalah melebihi penwaran barag-barang yang tersedia dalam perekonomian.

\section{Kebijakan Moneter Kuantitatif}

1) Melakukan Jual - beli surat-surat berharga didalam pasaran uang dan pasar modal (OPT); 2) Membuat perubahan ke atas suku diskonto dan suku bunga yang harus dibayar oleh bank-bank perdagangan; 3) Mengubah Tingkat Cadangan Minimum yang harus disimpan oleh bank-bank perdagangan.

\section{Ekspor}

Kegiatan ekspor maupun impor secara tidak langsung dapat menambah devisa dan kas negara. Ekspor adalah penjualan barang ke luar negri dengan menggunakan sistem pembayaran, kualitas, kuantitas dan sayarat penjualan lainnya yang telah disetujui oleh pihak eksportir dan importir (Nagari, 2016).

\section{METODE}

Metode yang digunakan adalah deskriptif yaitu teknik mengumpulkan, mengolah, menyederhanakan, menyajikan dan menganalisis data kuantitatif secara deskriptif agar dapat memberikan data yang eratur tentang suatu peristiwa. Tujuan dari peneitian deskriptif ini adalah untuk membuat suatu gambara secara sistematis factual dan akrual mengenai faktafakta realitinya,sifat-sifat serta hubungan antara fenomena yang sudah diselidiki.

\section{Definisi Variabel}

Pengertian variable menurut Sugiyono (2014: 38) adalah sebagai berikut: Variabel penelitian adalah suatu atribut atau sifat atau nilai orang, objek atau kegiatan yang mempunyai variasi yang tertentu yang diterapkan oleh peneliti untuk dipelajari dan kemudian ditarik kesimpulannya. Dalam penelitian yang dilakukan, variable yang digunaan adalah sebagai berikut: 1) Suku Bunga, Adalah imbal jasa atas pinjaman uang. Imbal jasa ini merupakan suatu kompensasi kepada pemberi pinjaman atas manfaat kedepan dari uang pinjman tersebut apabila diinvetasikan; 2) Inflasi, Adalah kenaikan dari harga- harga barang secara luas dan konstan atau terus menerus; 3) Nilai Tukar Rupiah, Adalah sebuah perjanjian yang dikenal sebagai nilai tukar mata uang terhadap pembayaran saat ini atau dikemudian hari, yaitu nilai tukar rupiah terhadap dollar Amerika Serikat; 4) Nilai ekspor, Adalah nilai berupa uang, termasuk semua biaya yang diminta atau seharusnya diminta oleh eksportir.

\section{HASIL DAN PEMBAHASAN}

Kebijakan Moneter The Federal Reserve Selama 15 bulan terakhir (Jan 2017- Feb 2018)

Federal Funds Rate (FFR) adalah suku bunga antarbank sebagai biaya pinjam-meminjam cadangan bank (bank reserves) yang ditempatkan oleh perbankan umum pada bank sentral Amerika dalam durasi semalam (overnight). Federal Funds Rate merupakan suku bunga acuan yang sangat penting bagi pelaku pasar finansial, baik di Amerika maupun di seluruh penjuru negeri.

\section{Tabel 1}

Perkembangan FFR selama 14 Bulan

\begin{tabular}{|c|c|c|}
\hline Bulan/T & Tahun & FFR $\quad(\%)$ \\
\hline Jan & 17 & 0,75 \\
\hline F e b & 17 & 0,75 \\
\hline $\mathrm{M}$ a r & 17 & 1,00 \\
\hline A p r & 17 & 1,00 \\
\hline $\mathrm{M}$ e i & 17 & 1,00 \\
\hline J u n & 17 & 1,25 \\
\hline $\mathrm{Ju} \mathrm{l}$ & 17 & 1,25 \\
\hline A g u & 17 & 1,25 \\
\hline S e p & 17 & 1,25 \\
\hline $\mathrm{O} \mathrm{kt}$ & 17 & 1,25 \\
\hline $\mathrm{Nov}$ & 17 & 1,25 \\
\hline D es & 17 & 1,25 \\
\hline $\mathrm{J}$ a n & 18 & 1,50 \\
\hline F e b & 18 & 1,50 \\
\hline
\end{tabular}

\section{Sumber : BI 2017}

Pada tahun 2016, Gubernur Bank Sentral AS, Jannet Yallen, telah memberikan tanda-tanda atau signal, bahwa pada tahun 2017, Bank Sentral AS akan menaikan suku bunga FFR sebanyak tiga kali. Hal ini terbukti benar.

Kenaikan suku bunga FFR tersebut memang sudah direncanakan oleh Pemerintah AS guna menarik kembali para investor Amerika Serikat yang memang sudah menanamkan modalnya di negara berkembang, agar kembali lagi menanamkan modalnya di Amerika Serikat.

Penaikan suku bunga FFR pada Juli 2017 (naik 25 basis dari 1.00\% menjadi 1.25\%) dilandasi oleh dua sasaran bank sentral, yaitu penyerapan lapangan kerja dan laju inflasi.

Sebagian besar ekonom AS meyakini bahwa perekonomian AS mendekati tingkat penyerapan penuh lapangan kerja atau kondisi di mana hampir seluruh orang yang sanggup dan mau bekerja sudah terserap di pasar tenaga kerja. 
Sedangkan data inflasi sudah melalui atau hanya sedikit di bawah target The Fed yang sebesar $2 \%$. Memasuki tahun 2018, FFR kembali mengalami peningkatan. The Fed mengekspektasikan bahwa tingkat inflasi pada tahun ini akan meningkat dan stabil sesuai dengan sasaran target The Fed , yaitu $2 \%$. Dengan adanya peningkatan suku bunga FFR, hal ini mengindikasikan bahwa terjadi juga peningkatan pada serapan tenaga kerja, belanja rumah tangga dan investasi dunia usaha, dan angka pengangguran tetap rendah.

Tabel 2

Suku Bunga The Fed dan BI 7 Days Reserve Repo

\begin{tabular}{|c|c|c|}
\hline $\begin{array}{l}\text { Bulan/ } \\
\text { Tahun }\end{array}$ & $\begin{array}{l}\text { FFR } \\
(\%)\end{array}$ & Inflasi (\%) \\
\hline $\begin{array}{ll}\text { Jan } 17 \\
\end{array}$ & 0,75 & 3,49 \\
\hline Feb 17 & 0,75 & 3,83 \\
\hline Mar 17 & 1,00 & 3,61 \\
\hline Apr 17 & 1,00 & 4,17 \\
\hline Mei 17 & 1,00 & 4,33 \\
\hline Jun 17 & 1,25 & 4,37 \\
\hline Jul 17 & 1,25 & 3,88 \\
\hline Agu 17 & 1,25 & 3,82 \\
\hline Sep 17 & 1,25 & 3,72 \\
\hline Okt 17 & 1,25 & 3,58 \\
\hline Nov 17 & 1,25 & 3,30 \\
\hline Des 17 & 1,25 & 3,61 \\
\hline Jan 18 & 1,50 & 3,25 \\
\hline Feb 18 & 1,50 & 3,18 \\
\hline
\end{tabular}

Sumber : BI 2017

\section{Efek The Fed Terhadap Suku Bunga Bank Indonesia ( BI 7 Days Repo)}

Reserve Repo (BI 7 Days Repo) merupakan suku bunga acuan yang digunakan oleh bank sentral dalam upaya mengendalikan suku bunga perbankan. Instrumen BI 7-Day Repo Rate sebagai acuan yang baru memiliki hubungan yang lebih kuat ke suku bunga pasar uang, sifatnya transaksional atau diperdagangkan di pasar, dan mendorong pendalaman pasar keuangan.

BI menilai, naiknya suku bunga The Fed tidak mempengaruhi suku bunga BI 7 Days Repo. Tingkat suku bunga acuan BI tidak hanya dipengaruhi oleh kondisi pasar keuangan dan kebijakan Internasional, tetapi juga dipengaruhi oleh kondisi perekonomian dan fundamental dalam negeri.

\section{Efek The Fed Terhadap Inflasi Indonesia}

Kenaikan suku bunga The Fed tidak terlalu berpengaruh terhadap pergerakan besarnya inflasi Indonesia. Hal ini dikarenakan pergerakan inflasi di Indonesia berpengaruh pada suku bunga BI 7 Days Reserve Repo. Hal ini berlawanan dengan hasil dari penelitian yang dilakukan oleh Lasma (Siahaan \&
Hidayat, 2013), yang menyebutkan bahwa tingkat suku bunga the fed memberi pengaruh yang signifikan terhadap suku bunga BI.

Tabel .3

Suku Bunga The Fed dan Inflasi Indonesia

\begin{tabular}{ccc}
\hline Bulan/ & & BI 7 Days \\
Tahun & FF R (\%) & Repo (\%) \\
\hline Jan 17 & 0,75 & 4,75 \\
Feb 17 & 0,75 & 4,75 \\
Mar 17 & 1,00 & 4,75 \\
Apr 17 & 1,00 & 4,75 \\
Mei 17 & 1,00 & 4,75 \\
Jun 17 & 1,25 & 4,75 \\
Jul 17 & 1,25 & 4,75 \\
Agu 17 & 1,25 & 4,50 \\
Sep 17 & 1,25 & 4,25 \\
Okt 17 & 1,25 & 4,25 \\
Nov 17 & 1,25 & 4,25 \\
Des 17 & 1,25 & 4,25 \\
Jan 18 & 1,50 & 4,25 \\
Feb 18 & 1,50 & 4,25 \\
\hline
\end{tabular}

Sumber: BI 2017

Efek The Fed Terhadap Pertukaran Nilai Kurs Rupiah

Tabel .4

Suku Bunga The Fed dan Kurs Rupiah

\begin{tabular}{|c|c|c|}
\hline $\begin{array}{l}\text { Bulan/ } \\
\text { Tahun } \\
\end{array}$ & $\begin{array}{l}\text { FFR } \\
(\%) \\
\end{array}$ & $\begin{array}{c}\text { Kurs Rp/USD } \\
\text { (Rp) }\end{array}$ \\
\hline Jan 17 & 0,75 & 13.410 \\
\hline Feb 17 & 0,75 & 13.414 \\
\hline Mar 17 & 1,00 & 13.388 \\
\hline Apr 17 & 1,00 & 13.394 \\
\hline Mei 17 & 1,00 & 13.388 \\
\hline Jun 17 & 1,25 & 13.386 \\
\hline Jul 17 & 1,25 & 13.390 \\
\hline Agu 17 & 1,25 & 13.418 \\
\hline Sep 17 & 1,25 & 13.559 \\
\hline Okt 17 & 1,25 & 13.640 \\
\hline Nov 17 & 1,25 & 13.582 \\
\hline Des 17 & 1,25 & 13.616 \\
\hline Jan 18 & 1,50 & 13.480 \\
\hline Feb 18 & 1,50 & 13.776 \\
\hline
\end{tabular}

Sumber : BI 2017

Menteri Keuangan RI, Ibu Sri Mulyani Indrawati, menilai bahwa nilai tukar rupiah terhadap Dollar AS masih cukup kompetitif meski sempat mengalami fluktuasi akibat membaiknya perekonomian AS.

Meskipun naiknya nilai kurs rupiah tidak terlalu 
banyak dan tidak terlalu kentara, tetapi tetap saja pergerakan nilai rupiah memperlihatkan kenaikan seiring dengan naiknya tingkat suku bunga the fed.

Efek The Fed Terhadap Nilai Ekspor Indonesia

Tabel .5

Suku Bunga The Fed dan Kurs Rupiah

\begin{tabular}{cc}
\hline $\begin{array}{c}\text { Bulan/ } \\
\text { Tahun }\end{array}$ & Nilai Expor Indonesia (Rp) \\
\hline Jan 17 & 179.716 .851 .282 .205 \\
Feb 17 & 169.197 .789 .184 .528 \\
Mar 17 & 196.519 .883 .947 .846 \\
Apr 17 & 177.861 .439 .978 .258 \\
Mei 17 & 192.056 .093 .081 .224 \\
Jun 17 & 156.026 .054 .051 .829 \\
Jul 17 & 182.254 .092 .388 .280 \\
Agu 17 & 204.348 .339 .427 .317 \\
Sep 17 & 197.415 .701 .291 .093 \\
Okt 17 & 207.903 .630 .184 .778 \\
Nov 17 & 208.079 .514 .082 .760 \\
Des 17 & 202.515 .044 .143 .469 \\
Jan 18 & 196.179 .896 .596 .295 \\
Feb 18 & 194.241 .600 .000 .138 \\
\hline
\end{tabular}

Sumber : BI dan OJK

Terkait dengan artikel yang dimuat pada harian RMOL Jabar mengenai dampak FFR pada Ekspor Indonesia, yang menyatakan bahwa perekonomian global akan semakin membaik, terutama di negara maju. Relatif membaiknya pertumbuhan ekonomi global dan tetap tingginya harga komoditas dunia berdampak positif terhadap kinerja ekspor Indonesia.

Sementara itu, risiko pasar keuangan global relatif terjaga seiring dengan keputusan Federal Open Market Commite (FOMC) terkait dengan kebijakan Fed Funds Rate (FFR) dan normalisasi neraca bank sentral AS yang sesuai dengan perkiraan pasar. Juga, keputusan FOMC tersebut sejalan dengan perkiraan dari Bank Indonesia (BI) (ALDI FERDIAN, 2017).

Pada tabel diatas, terlihat bahwa perkembangan atau dengan meningkatnya suku bunga the fed cukup berpengaruh terhadap nilai ekspor indonesia. Hal ini dikarena kegiatan ekspor adalah kegiatan menjual barang hasil produksi Indonesia ke luar Indonesia, sehingga suku bunga yang digunakan oleh transaksi ekspor bukan lagi suku bunga BI 7 Days Repo, melainkan suku bunga the fed.

\section{KESIMPULAN DAN SARAN}

\section{KESIMPULAN}

1) Kebijakan moneter yang dilakukan oleh TheFederal Reserve AS dalam upayanya untuk memperbaiki perekonomian AS adalah menaikan tingkat suku bunga FFR secara bertahap; 2) Naiknya suku bunga the fed tidak mempengaruhi suku bunga BI 7 Days Repo; 3) Kenaikan tingkat suku bunga the fed tidak berpengaruh terhadap pergerakan inflasi di Indonesia; 4) Kenaikan suku bunga the fed mempengaruhi nilai tukar Rupiah terhadap Dollar AS; 5) Kenaikan suku bunga the fed mempengaruhi nilai ekspor Indonesia.

\section{SARAN}

1) Pemerintah Indonesia lebih fokus kepada kesejahteraan rakyat, terutama pada tingkat suku bunga, karena suku bunga merupakan salah satu kunci dari kegiatan perbankan; 2) Untuk penelitian berikutnya, diharapkan agar peneliti lainnya dapat menambah variabel lain; 3) Agar menggunakan alat uji seperti SPSS agar mendapatkan hasil yang relevan dan lebih pasti.

\section{DAFTAR PUSTAKA}

Aldi Ferdian (2017). Dampak Perekonomian Global Berimbas Positif Pada Laju Ekspor Indonesia. Retrieved from http://www.rmoljabar.com/read/2017/ 10/10/56814/Dampak-Perekonomian-GlobalBerimbas-Positif-Pada-Laju-Ekspor-Indonesia-

Andrianus, Ferry dan Amalia Niko. 2006. Analisa FaktorFaktor Yang Mempengaruhi Inflasi Di Indonesia Periode Maret 1997 - Februari 2005. Jurnal Ekonomi Pembangunan. Vol. II, No 2.

Budi, Chandra, Komarina L Hastuti D, Suriadi. 2009. AnalisisPengaruh Tingkat SukuBunga SBI Terhadap variable Makroekonomi di Indonesia Periode 1990-2008.JurnalEkonomi Pembangunan FakultasEkonomiUniversitasSiliwangi.

Eiteman, K. David, Moffet, H. Michael, dan Stonehill, I. Arthur. 2007. Manajemen Keuangan Multinasional, Edisi Kesebelas, Erlangga, Jakarta.

Frank J. Fabozzi, 2011. Pasar dan Lembaga Keuangan 1. Edisi Indonesia, Jakarta : Salemba Empat.

Hamdani. (2012). kspor Impor Tingkat Dasar Level Satu. Jakarta: Bushindo.

Haryati, Sri. Pertumbuhan Kredit Perbankan Di Indonesia : Intermediasi dan Pengaruh Variabel Makro Ekonomi. Jurnal Keuangan dan Perbankan. Vol.13. No.2. Surabaya, 2009.

Hendro, Tri dan Conny Tjandra Raharja. 2014. Bank dan Institusi Keuangan non Bank di Indonesia. Yogyakarta : UPP STIM YKPN. 
Hertiana, Ikasari. 2005. Determinasi Inflasi (Pendekatan Klasik). Thesis, Univeristas Diponogoro. Semarang.

Linda,Seprillina2013. Efektivitas Instrumen KebijakanMoneter Terhadap Pertumbuhan ekonomi di Indonesia Periode 1999 2012.Indonesian Publication Index. Jurnal Ilmiah Mahasiswa Fakultas Ekonomi dan Bisnis Universitas Brawijaya. Malang.

Manullang, Drs, M. (1977). Pengantar Teori Ekonomi Moneter. Jakarta: Ghalia Indonesia.

Maqrobi, Syaiful dan Pijiatu Amin. 2011. Inflasi dan Pertumbuhan Ekonomi : Uji Klausatif Inflastion and Economic Growth: Testing for Causality. Dinamika Keuangan dan Perbankan. Vol.3, No 1. Mei 2011.

Muhammad Edhie Purnawan, P. . (2016). The Federal Funds Rate, BI, dan Siklus Bisnis. Retrieved from http://macroeconomicdashboard.feb.ugm.ac.id/thefederal-funds-rate-bi-dan-siklus-bisnis/

Nagari, A. A. (2016). TEKSTIL DAN PRODUK TEKSTIL INDONESIA ( Studi Pada Tahun 2010-2016 ), 53(1), 202-210.

Pragiwaksana, AngilbertEnggar. 2016. Dampak Penyelesaian Transaksi Operasi Moneter Terhadap Tingkat Inflasi dan Stabilitas Nilai Tukar Rupiah Di Bank Indonesia. Skripsi Fakultas Ekonomi dan Bisnis, Universitas Pancasila, Jakarta.

Pratiwi, Andianing. 2013. Determinasi Inflasi di Indonesia Analisis Jangka Panjang dan Pendek. Jurnal Ilmiah Fakultas Ekonomi dan Bisnis Universitas Brawijaya. Malang

Putong, Iskandar. 2008. Pengantar Ekonomi Mikro dan Makro. Jakarta : Mitra Wacana Media.
Rohim, Fakthur. 2011. Mekanisme Transmisi Kebijakan Moneter Melalui Suku Bunga SBI Sebagai Sasaran Operasional Kebijakan Moneter dan Variabel Makroekonomi di Indonesia. Thesis. Medan : Universitas Sumatra Utara.Sartono,Agus.2010. Manajemen Keuangan Teori dan Aplikasi. Edisi 4. Yogyakarta : BPFE.

Siahaan, L. M., \& Hidayat, P. (2013). Analisis Kausalitas dan Kointegrasi Antara Tingkat Suku Bunga Bank Indonesia (BI Rate) dengan Suku Bunga Bank Amerika Serikat (the Fed). Jurnal Ekonomi Dan Keuangan, 1(2009), 49-60.

Sipayang, Enistin Tista Putri. 2013. Pengaruh PDB, Nilai Tukar dan Jumlah Uang Beredar Terhadap Inflasi di Indonesia_Periode 1993 - 2012. E-Journal Ekonomi Pembangunan Universitas Udayana. Vol. 2, No 7. 7 Juli 2013

Sukirno, Sadono. 2004. MakroekonomiTeoriPengantar. Edisi Ketiga. Jakarta : PT. Raja Grafindo Persada.

Sutawijaya, Adrian. 2012. Pengaruh Faktor-Faktor Ekonomi Terhadap Inflasi Di Indonesia. Jurnal Organisasi dan Manajemen. Vol.8. No.2

Tri, Hendro dan Rahardja Tjandra Conny. 2014. Bank Dan Institusi Keuangan Non Bank Di Indonesia. Yogyakarta : UPP STIM YKPN.

Yassirli, Aimon Hadi dan Syofyan Efrizal. Analisis Pengaruh Kebijakan Moneter Terhadap Inflasi dan Perekonomian di Indonesia. Ejournal.up.ac.id.

http://macroeconomicdashboard.feb.ugm.ac.id/ pertumbuhan-ekonomi-dan-penyaluran-kredit/

www.bi.go.id.

www.bps.go.id

www.indonesia-investments.com/id/keuangan/angkaekonomi-makro/inflasi-di-indonesia

www.ojk.go.id 